(1)

CrossMark

\title{
Association of asthma and smoking with lung function impairment in adolescence and early adulthood: the Isle of Wight Birth Cohort Study
}

\author{
S. Hasan Arshad ${ }^{1,2,3}$, Claire Hodgekiss ${ }^{1}$, John W. Holloway $\mathbb{1}^{4}$, \\ Ramesh Kurukulaaratchy ${ }^{1,2,3}$, Wilfried Karmaus ${ }^{5}$, Hongmei Zhang ${ }^{5}$ and \\ Graham Roberts ${ }^{1,2,3}$
}

Affiliations: ${ }^{1}$ The David Hide Asthma and Allergy Research Centre, Newport, UK. ${ }^{2}$ Clinical and Experimental Sciences, Faculty of Medicine, University of Southampton, Southampton, UK. ${ }^{3}$ Respiratory Biomedical Centre, University Hospital Southampton, Southampton, UK. ${ }^{4}$ Human Development and Health, Faculty of Medicine, University of Southampton, Southampton, UK. ${ }^{5}$ Division of Epidemiology, Biostatistics, and Environmental Health, School of Public Health, University of Memphis, Memphis, TN, USA.

Correspondence: S. Hasan Arshad, 810, South Block, Southampton General Hospital, Tremona Road, Southampton, UK. E-mail: shadsoton.ac.uk

@ERSpublications

Asthma is associated with reduced lung function growth between 10 and 18 years; smoking is associated with decline between 18 and 26 years. Both may increase susceptibility to COPD, emphasising a potential benefit of intervention to prevent lung damage. http://bit.ly/33yPZyM

Cite this article as: Arshad SH, Hodgekiss C, Holloway JW, et al. Association of asthma and smoking with lung function impairment in adolescence and early adulthood: the Isle of Wight Birth Cohort Study. Eur Respir J 2020; 55: 1900477 [https://doi.org/10.1183/13993003.00477-2019].

ABSTRACT We investigated associations of asthma and smoking with lung function and airway reversibility from childhood to early adulthood.

The population-based Isle of Wight Birth Cohort $(\mathrm{n}=1456)$ was assessed at birth, and at 1, 2, 4, 10, 18 and 26 years. Asthma was defined as physician diagnosis plus current wheeze and/or treatment. Spirometry was conducted at $10(\mathrm{n}=981), 18(\mathrm{n}=839)$ and 26 years $(\mathrm{n}=547)$. Individuals were subdivided into nonsmokers without asthma, nonsmokers with asthma, smokers without asthma and smokers with asthma, based on asthma and smoking status at 26 years. Their lung function trajectories from 10 to 26 years were examined using longitudinal models.

Nonsmokers with asthma had smaller forced expiratory volume in $1 \mathrm{~s}\left(\mathrm{FEV}_{1}\right), \mathrm{FEF}_{25-75 \%}$ (forced expiratory flow at $25-75 \%$ of forced vital capacity (FVC)) and $\mathrm{FEV}_{1} / \mathrm{FVC}$ ratio compared to nonsmokers without asthma at age 10 and 18 years, with differences reduced after bronchodilator (pre-bronchodilator $\mathrm{FEV}_{1}$ at 26 years 3.75 L versus $4.02 \mathrm{~L}, \mathrm{p}<0.001$; post-bronchodilator $4.02 \mathrm{~L}$ versus $4.16 \mathrm{~L}, \mathrm{p}=0.08$ ). This lung function deficit did not worsen after 18 years. Smokers without asthma had smaller $\mathrm{FEF}_{25-75 \%}$ and $\mathrm{FEV}_{1} / \mathrm{FVC}$ ratio (but not $\mathrm{FEV}_{1}$ ) at 26 years compared to nonsmokers without asthma, with the deficit appearing after 18 years and persisting despite bronchodilator response (for $\mathrm{FEV}_{1} / \mathrm{FVC}$ ratio at 26 years 0.80 versus $0.81, \mathrm{p}=0.002$; post-bronchodilator 0.83 versus $0.85, \mathrm{p}=0.005)$. Smokers with asthma had worse lung function compared to other groups.

Lung function deficits associated with asthma and smoking occur early in life. They are not fully responsive to bronchodilators, indicating a risk for long-term lung health, which highlights the need to institute preventive measures in adolescence and early adult life before irreversible damage occurs.

This article as an editorial commentary: https://doi.org/10.1183/13993003.02457-2019

This article has supplementary material available from erj.ersjournals.com

Received: 6 March 2019 | Accepted after revision: 22 Nov 2019

Copyright OERS 2020 


\section{Introduction}

The normal trajectory of forced expiratory volume in $1 \mathrm{~s}\left(\mathrm{FEV}_{1}\right)$ shows age- and height-related growth during childhood and adolescence, but age-related decline in adulthood [1]. When exactly this decline starts might depend on factors such as sex, and on childhood conditions such as asthma [2,3]. A lower $\mathrm{FEV}_{1}$ strongly correlates with lifelong morbidity and higher mortality [4]. Recent studies have suggested that a low $\mathrm{FEV}_{1}(<80 \%$ predicted) in young adult life (age $<40$ years) increases the risk of chronic obstructive pulmonary disease (COPD) several-fold in later life, despite a normal age-related decline of lung function [5]. Specifically, in smokers, $\mathrm{FEV}_{1}$ declines rapidly, resulting in irreversible airways obstruction $[1,6]$. However, there appears to be considerable variability in individual susceptibility to the deleterious effects of smoking on lung function [1]. Identification of susceptible smokers early in the course of disease before irreversible damage occurs is vital for targeting preventive strategies such as early smoking cessation, which are known to slow age-related decline in lung function [1].

Persistent childhood asthma is probably one of the major factors determining lower lung function and risk for fixed airflow obstruction in young adult life [7-9]. Asthma may also increase susceptibility to deleterious effects of smoking [1]. Those who smoke and/or have asthma in early adult life have increased risk of COPD, so it is important to investigate the relative contribution of these two exposures on the most sensitive lung function indices, and to establish when decline in lung function commences.

The Isle of Wight birth cohort was examined at ages 10, 18 and 26 years for lung function and asthma, while information on environmental exposures, including active and passive smoking, were obtained since birth. In this study we determined the association of current asthma and smoking (assessed at age 26 years) with lung function from childhood to early adult life. We hypothesised that 1) lung function decline starts in childhood in those with asthma and by mid-twenties in those who smoke, and 2) in smokers the resulting deficit has less bronchodilator reversibility compared to those with asthma.

\section{Materials and methods \\ Design and participants}

The Isle of Wight birth cohort is a prospective population-based cohort study investigating prevalence, natural history and risk and protective factors for the development of asthma, lung function and allergic diseases. All children $(\mathrm{n}=1536)$ born at St Mary's Hospital on the Isle of Wight between January 1, 1989 and February 28, 1990 were enrolled, with 1456 consenting to long-term follow-up, which has so far been conducted at the ages of $1,2,4,10,18$ and 26 years [10]. The retention rate was $>80 \%$ at all assessments up to 18 years and it was $71 \%$ at 26 years. A wide range of phenotypic and environmental information has been collected using questionnaires and hospital medical records, study procedures such as skin-prick test, spirometry, methacholine bronchial challenge and exhaled nitric oxide, and $>10000$ biological samples have been collected (supplementary table S1). All participants provided informed consent and ethical approval was obtained from the local/national research ethics committee at recruitment and at each assessment. At age 26 years, ethical approval was granted by the West Midlands research ethics committee (reference 15/WM/0071). The analysis and manuscript follows STROBE (Strengthening the Reporting of Observational Studies in Epidemiology) statement [11].

\section{Asthma and smoking assessment}

Validated questionnaires were completed at face-to-face interview or telephone/postal/web questionnaires. The majority of participants attending in person underwent spirometry at 10, 18, and 26 years and bronchodilator reversibility at 18 and 26 years. Details of questionnaires and other assessments have been reported previously $[12,13]$. Briefly, both study-specific and International Study of Asthma and Allergies in Childhood questionnaires were completed for detailed assessment of asthma symptoms and treatment. Current asthma was defined as physician diagnosis plus current wheeze and/or on treatment for wheeze/ asthma. Information on environmental risk factors was collected from birth up to age 26 years including current and past cigarette smoking and asthma treatment use.

Four groups were defined and compared based on the presence of current asthma and/or current smoking at 26 years. In this context, participants with a diagnosis of asthma at 26 years were regarded as having asthma, irrespective of previous status. Similarly, those who were smoking at 26 years, were regarded as smoking, irrespective of previous smoking status. This gave four groups: 1) nonsmokers without asthma; 2) nonsmokers with asthma; 3) smokers without asthma; and 4) smokers with asthma.

\section{Lung function assessment}

Pre-bronchodilator spirometry was performed at ages $10(\mathrm{n}=981), 18(\mathrm{n}=839)$ and 26 years $(\mathrm{n}=547)$ and post-bronchodilator spirometry at $18(\mathrm{n}=791)$ and 26 years $(\mathrm{n}=535)$, to allow assessment of changes in lung function over the rapid growth period of adolescence and to estimate early decline that might occur 
in high-risk subpopulations due to underlying conditions, such as asthma, or exposures, such as smoking. The subgroup with lung function data were not different in basic characteristics such as sex, smoking and allergic history to all the cohort members who participated at the 26-years assessment (supplementary table S2). For spirometry, American Thoracic Society/European Respiratory Society guidelines were followed to ensure validity and reproducibility [14]. Koko Spirometers (Longmont, CO, USA) were used, with calibration performed at least once daily. To perform spirometry, participants had to be free from respiratory infection for 14 days, not taking oral steroids, not having taken $\beta_{2}$-agonists for $6 \mathrm{~h}$ and abstained from caffeine intake for $\geqslant 4 \mathrm{~h}$. Spirometry was performed with participants standing without nose-clip. The acceptability criteria for each effort included a satisfactory start and end of test as well as a plateau in the volume-time curve [14]. $\mathrm{FEV}_{1}$, forced vital capacity (FVC), $\mathrm{FEV}_{1} / \mathrm{FVC}$ ratio and forced expiratory flow at $25-75 \%$ of $\mathrm{FVC}\left(\mathrm{FEF}_{25-75 \%}\right)$ were recorded. As recommended, the highest of three $\mathrm{FEV}_{1}$ measurements within $5 \%$ of each other was used. Changes in $\mathrm{FEV}_{1}, \mathrm{FEV}_{1} / \mathrm{FVC}$ ratio and $\mathrm{FEF}_{25-75 \%}$ between assessments were calculated as the difference between values at 10 and 18 years and then 18 and 26 years. Predicted percentage values for age, height, sex and ethnic origin were calculated for the $\mathrm{FEV}_{1}$, FVC, $\mathrm{FEV}_{1} / \mathrm{FVC}$ ratio and $\mathrm{FEF}_{25-75 \%}$ based on Global Lung Initiative reference equations [15]. Bronchodilator reversibility was performed at 18 and 26 years. Post-bronchodilator values were obtained $20 \mathrm{~min}$ after inhalation of $600 \mu \mathrm{g}$ salbutamol using a metered dose inhaler via a large-volume spacer. Significant reversibility was defined as $\geqslant 12 \%$ increase in $\mathrm{FEV}_{1}$.

\section{Statistical analysis}

To examine associations between these four groups, longitudinal models were utilised. These longitudinal models were applied and inferred using generalised estimating equations to give population averaged estimates. Models included sex, time and asthma/smoking group plus their interaction terms as adjusting factors. The dependent lung function parameters, were estimated for the 10-18 years and 18-26 years time frames adjusted for sex to maximise the number of participants included. As sensitivity analyses, we repeated the analysis with the 10-, 18- and 26-year time points in one model, and controlled for height at assessment by using percentage predicted lung function parameters (supplementary material). To examine the change in lung function parameters in individual participants, a regression model was used controlling for sex. STATA (v14; StataCorp, College Station, TS, USA) was used for these data analyses. A p-value $<0.05$ was taken to indicate statistical significance.

\section{Results}

Based on their asthma and smoking status at 26 years, there were 600 (58.3\%) nonsmokers without asthma, 108 (10.5\%) nonsmokers with asthma, 270 (26.2\%) smokers without asthma and 52 (5.0\%) smokers with asthma. Characteristics of nonsmokers with asthma, smokers without asthma and smokers with asthma at the age of 26 years are provided in supplementary table S1. Mean age for smoking initiation was 16 years and thus most smokers had $\sim 10$ years of personal smoking duration. Supplementary table S3 provides lung function data at 10, 18 and 26 years stratified by sex.

\section{Differences in lung function between groups at each assessment (10, 18 and 26 years)}

Looking at the longitudinal model, nonsmokers with asthma compared to nonsmokers without asthma at 26 years had a smaller pre-bronchodilator $\mathrm{FEV}_{1}$ and $\mathrm{FEF}_{25-75 \%}$ at 18 and 26 years ( 9\%) and $\mathrm{FEV}_{1} / \mathrm{FVC}$ ratio at all assessments (table 1 and figure 1). With narrowing of the difference following bronchodilator, the statistical significance of the difference was lost at 26 years for post-bronchodilator $\mathrm{FEV}_{1}$ and $\mathrm{FEV}_{1} /$ FVC ratio. $\mathrm{FEV}_{1} / \mathrm{FVC}$ and $\mathrm{FEF}_{25-75 \%}$ were lower in smokers without asthma (3.76 versus $4.05 \mathrm{~L}, \mathrm{p}<0.001$ and 0.80 versus $0.81, \mathrm{p}=0.002$, respectively), compared to control, with the difference persisting after bronchodilation (table 1). Apart from FVC, all lung function parameters in smokers with asthma at 26 years were much lower than for nonsmokers without asthma, even after bronchodilator (table 1).

Smokers with asthma show proportionally less bronchodilator reversibility for $\mathrm{FEV}_{1} / \mathrm{FVC}$ and for $\mathrm{FEF}_{25-75 \%}$ than nonsmokers with asthma (table 1). In contrast, both pre- and post-bronchodilator $\mathrm{FEV}_{1}$, $\mathrm{FEV}_{1} / \mathrm{FVC}$ and $\mathrm{FEF}_{25-75 \%}$ were smaller at the 26-year assessment in smokers with asthma compared to smokers without asthma (table 1). The pattern of lung function remained the same in the four groups in the subset which included participants with lung function data at all three time points (supplementary figure S1). A sensitivity analysis on these participants using percentage predicted values revealed no important changes in lung function trajectories (supplementary figure S2).

\section{Changes in lung function across adolescence and early adulthood}

Over adolescence, nonsmokers with asthma had a smaller increase in $\mathrm{FEV}_{1}$ (10-18 years change 1.84 versus $2.06 \mathrm{~L}, \mathrm{p}<0.001)$ and $\mathrm{FEF}_{25-75 \%}(10-18$ years change 1.82 versus $2.13 \mathrm{~L}, \mathrm{p}<0.01)$ when compared to nonsmokers without asthma, but not between 18 and 26 years in the longitudinal model (figure 2). Smokers 
TABLE 1 Association of asthma and smoking status on pre- and post-bronchodilator spirometry at 10,18 and 26 years

\begin{tabular}{|c|c|c|c|c|c|c|c|c|c|c|c|c|}
\hline & \multicolumn{4}{|c|}{10 years } & \multicolumn{4}{|c|}{18 years } & \multicolumn{4}{|c|}{26 years } \\
\hline & $\begin{array}{l}\text { Nonsmokers } \\
\text { without } \\
\text { asthma }\end{array}$ & $\begin{array}{l}\text { Nonsmokers } \\
\text { with asthma }\end{array}$ & Difference & p-value & $\begin{array}{l}\text { Nonsmokers } \\
\text { without } \\
\text { asthma }\end{array}$ & $\begin{array}{l}\text { Nonsmokers } \\
\text { with asthma }\end{array}$ & Difference & p-value & $\begin{array}{l}\text { Nonsmokers } \\
\text { without } \\
\text { asthma }\end{array}$ & $\begin{array}{l}\text { Nonsmokers } \\
\text { with asthma }\end{array}$ & Difference & p-value \\
\hline \multicolumn{13}{|c|}{ Nonsmokers with asthma versus nonsmokers without asthma } \\
\hline Subjects $\mathrm{n}$ & 422 & 80 & & & 417 & 74 & & & 313 & 62 & & \\
\hline $\mathrm{FEV}_{1} \mathrm{~L}$ & 2.04 & 2.00 & $-0.05(-0.16-0.04)$ & 0.273 & 4.05 & 3.77 & $-0.27(-0.37--0.17)$ & $<0.001$ & 4.02 & 3.75 & $-0.28(-0.41--0.14)$ & $<0.001$ \\
\hline $\begin{array}{l}\text { Post-bronchodilator } \\
\text { FEV } 1 \text { L }\end{array}$ & & & & & 4.18 & 4.02 & $-0.16(-0.30--0.02)$ & 0.023 & 4.16 & 4.02 & $-0.13(-0.28-0.02)$ & 0.078 \\
\hline FVC L & 2.30 & 2.31 & $0.00(-0.12-0.12)$ & 0.984 & 4.60 & 4.46 & $-0.14(-0.26-0.02)$ & 0.024 & 4.96 & 4.90 & $-0.06(-0.22-0.11)$ & 0.497 \\
\hline $\begin{array}{l}\text { Post-bronchodilator } \\
\text { FVC L }\end{array}$ & & & & & 4.63 & 4.56 & $-0.08(-0.24-0.08)$ & 0.322 & 4.92 & 4.87 & $-0.06(-0.22-0.11)$ & 0.510 \\
\hline $\mathrm{FEV}_{1} / \mathrm{FVC}$ & 0.89 & 0.87 & $-0.03(-0.04--0.01)$ & $<0.001$ & 0.88 & 0.85 & $-0.03(-0.05--0.02)$ & $<0.001$ & 0.81 & 0.77 & $-0.04(-0.06--0.03)$ & $<0.001$ \\
\hline $\begin{array}{l}\text { Post-bronchodilator } \\
\mathrm{FEV}_{1} / \mathrm{FVC}\end{array}$ & & & & & 0.91 & 0.89 & $-0.02(-0.03--0.01)$ & 0.021 & 0.85 & 0.83 & $-0.02(-0.03-0.00)$ & 0.052 \\
\hline $\mathrm{FEF}_{25-75 \% \mathrm{~L}}$ & 2.49 & 2.25 & $-0.25(-0.440--0.059)$ & 0.010 & 4.56 & 4.00 & $-0.56(-0.75--0.36)$ & $<0.001$ & 4.05 & 3.31 & $-0.75(-1.01--0.49)$ & $<0.001$ \\
\hline Post-bronchodilator & & & & & 4.98 & 4.56 & $-0.42(-0.67--0.17)$ & 0.001 & 4.64 & 4.24 & $-0.40(-0.67--0.13)$ & 0.004 \\
\hline \multirow{2}{*}{\multicolumn{13}{|c|}{$\begin{array}{l}\mathrm{FEF}_{25-75 \%} \mathrm{~L} \\
\text { Smokers without asthma versus nonsmokers without asthma }\end{array}$}} \\
\hline & & & & & & & & & & & & \\
\hline Subjects $\mathrm{n}$ & 422 & 203 & & & 417 & 176 & & & 313 & 142 & & \\
\hline $\mathrm{FEV}_{1} \mathrm{~L}$ & 2.04 & 2.03 & $-0.02(-0.09-0.05)$ & 0.526 & 4.05 & 4.00 & $-0.05(-0.12-0.02)$ & 0.149 & 4.02 & 3.93 & $-0.10(-0.19-0.00)$ & 0.052 \\
\hline $\begin{array}{l}\text { Post-bronchodilator } \\
\qquad \mathrm{FEV}_{1} \mathrm{~L}\end{array}$ & & & & & 4.18 & 4.18 & $0.00(-0.10-0.10)$ & 0.975 & 4.16 & 4.08 & $-0.08(-0.18-0.02)$ & 0.131 \\
\hline FVC L & 2.30 & 2.28 & $-0.03(-0.11-0.05)$ & 0.506 & 4.60 & 4.59 & $-0.02(-0.10-0.06)$ & 0.617 & 4.96 & 4.97 & $0.01(-0.10-0.12)$ & 0.863 \\
\hline $\begin{array}{l}\text { Post-bronchodilator } \\
\text { FVC L }\end{array}$ & & & & & 4.63 & 4.66 & $0.03(-0.09-0.14)$ & 0.643 & 4.92 & 4.93 & $0.00(-0.11-0.12)$ & 0.970 \\
\hline $\mathrm{FEV}_{1} / \mathrm{FVC}$ & 0.89 & 0.89 & $0.00(-0.01-0.01)$ & 0.645 & 0.88 & 0.87 & $-0.01(-0.02-0.00)$ & 0.075 & 0.81 & 0.80 & $-0.02(-0.03--0.01)$ & 0.002 \\
\hline $\begin{array}{l}\text { Post-bronchodilator } \\
\mathrm{FEV}_{1} / \mathrm{FVC}\end{array}$ & & & & & 0.91 & 0.90 & $-0.01(-0.02-0.01)$ & 0.359 & 0.85 & 0.83 & $-0.02(-0.03--0.01)$ & 0.005 \\
\hline $\mathrm{FEF}_{25-75 \%} \mathrm{~L}$ & 2.49 & 2.44 & $-0.05(-0.18-0.08)$ & 0.465 & 4.56 & 4.47 & $-0.10(-0.23-0.04)$ & 0.157 & 4.05 & 3.76 & $-0.31(-0.49--0.13)$ & 0.001 \\
\hline Post-bronchodilator & & & & & 4.98 & 4.90 & $-0.09(-0.27-0.08)$ & 0.299 & 4.64 & 4.38 & $-0.27(-0.46--0.09)$ & 0.004 \\
\hline $\mathrm{FEF}_{25-75 \% \mathrm{~L}}$ & & & & & & & & & & & & \\
\hline \multicolumn{13}{|c|}{ Smokers with asthma versus nonsmokers without asthma } \\
\hline Subjects $\mathrm{n}$ & 422 & 40 & & & 417 & 32 & & & 313 & 30 & & \\
\hline $\mathrm{FEV}_{1} \mathrm{~L}$ & 2.04 & 2.01 & $-0.04(-0.18-0.08)$ & 0.469 & 4.05 & 3.73 & $-0.33(-0.48--0.19)$ & $<0.001$ & 4.02 & 3.74 & $-0.30(-0.49--0.12)$ & 0.001 \\
\hline $\begin{array}{l}\text { Post-bronchodilator } \\
\qquad \mathrm{FEV}_{1} \mathrm{~L}\end{array}$ & & & & & 4.18 & 4.03 & $-0.17(-0.36-0.02)$ & 0.080 & 4.16 & 3.95 & $-0.23(-0.42--0.03)$ & 0.021 \\
\hline FVC L & 2.30 & 2.32 & $0.01(-0.14-0.17)$ & 0.858 & 4.60 & 4.60 & $-0.01(-0.18-0.16)$ & 0.894 & 4.96 & 4.96 & $0.00(-0.22-0.22)$ & 0.99 \\
\hline $\begin{array}{l}\text { Post-bronchodilator } \\
\text { FVC L }\end{array}$ & & & & & 4.63 & 4.72 & $0.08(-0.14-0.30)$ & 0.483 & 4.92 & 5.03 & $0.11(-0.12-0.33)$ & 0.351 \\
\hline $\mathrm{FEV}_{1} / \mathrm{FVC}$ & 0.89 & 0.86 & $-0.03(-0.05--0.01)$ & 0.002 & 0.88 & 0.82 & $-0.06(-0.09--0.04)$ & $<0.001$ & 0.81 & 0.76 & $-0.06(-0.08--0.04)$ & $<0.001$ \\
\hline $\begin{array}{l}\text { Post-bronchodilator } \\
\mathrm{FEV}_{1} / \mathrm{FVC}\end{array}$ & & & & & 0.91 & 0.86 & $-0.05(-0.07--0.03)$ & $<0.001$ & 0.85 & 0.79 & $-0.06(-0.08--0.04)$ & $<0.001$ \\
\hline $\mathrm{FEF}_{25-75 \%} \mathrm{~L}$ & 2.49 & 2.22 & $-0.28(-0.54--0.03)$ & 0.027 & 4.56 & 3.66 & $-0.93(-1.21--0.65)$ & $<0.001$ & 4.05 & 3.15 & $-0.93(-1.28--0.59)$ & $<0.001$ \\
\hline Post-bronchodilator & & & & & 4.98 & 4.30 & $-0.74(-1.09--0.38)$ & $<0.001$ & 4.64 & 3.67 & $-1.00(-1.36--0.65)$ & $<0.001$ \\
\hline \multirow{2}{*}{\multicolumn{13}{|c|}{ Smokers with asthma versus nonsmokers with asthma }} \\
\hline & & & & & & & & & & & & \\
\hline Subjects $\mathrm{n}$ & 80 & 40 & & & 74 & 32 & & & 62 & 30 & & \\
\hline $\mathrm{FEV}_{1} \mathrm{~L}$ & 2.00 & 2.01 & $0.01(-0.15-0.17)$ & 0.930 & 3.77 & 3.73 & $-0.06(-0.23-0.11)$ & 0.483 & 3.75 & 3.74 & $-0.03(-0.24-0.19)$ & 0.813 \\
\hline $\begin{array}{l}\text { Post-bronchodilator } \\
\qquad \mathrm{FEV}_{1} \mathrm{~L}\end{array}$ & & & & & 4.02 & 4.03 & $-0.01(-0.23-0.21)$ & 0.925 & 4.02 & 3.95 & $-0.09(-0.32-0.13)$ & 0.414 \\
\hline FVCL & 2.31 & 2.32 & $0.02(-0.17-0.20)$ & 0.869 & 4.46 & 4.60 & $0.13(-0.07-0.32)$ & 0.215 & 4.90 & 4.96 & $0.06(-0.20-0.31)$ & 0.676 \\
\hline $\begin{array}{l}\text { Post-bronchodilator } \\
\text { FVC L }\end{array}$ & & & & & 4.56 & 4.72 & $0.16(-0.10-0.42)$ & 0.225 & 4.87 & 5.03 & $0.16(-0.10-0.43)$ & 0.227 \\
\hline $\mathrm{FEV}_{1} / \mathrm{FVC}$ & 0.87 & 0.86 & $-0.01(-0.03-0.02)$ & 0.690 & 0.85 & 0.82 & $-0.03(-0.06-0.00)$ & 0.022 & 0.77 & 0.76 & $-0.02(-0.04-0.01)$ & 0.312 \\
\hline
\end{tabular}




\begin{tabular}{|c|c|c|c|c|c|c|c|c|c|c|c|c|}
\hline & \multicolumn{4}{|c|}{10 years } & \multicolumn{4}{|c|}{18 years } & \multicolumn{4}{|c|}{26 years } \\
\hline & $\begin{array}{c}\text { Nonsmokers } \\
\text { without } \\
\text { asthma }\end{array}$ & $\begin{array}{l}\text { Nonsmokers } \\
\text { with asthma }\end{array}$ & Difference & $\mathrm{p}$-value & $\begin{array}{l}\text { Nonsmokers } \\
\text { without } \\
\text { asthma }\end{array}$ & $\begin{array}{l}\text { Nonsmokers } \\
\text { with asthma }\end{array}$ & Difference & $\mathrm{p}$-value & $\begin{array}{l}\text { Nonsmokers } \\
\text { without } \\
\text { asthma }\end{array}$ & $\begin{array}{l}\text { Nonsmokers } \\
\text { with asthma }\end{array}$ & Difference & p-value \\
\hline $\begin{array}{l}\text { Post-bronchodilator } \\
\mathrm{FEV}_{1} / \mathrm{FVC}\end{array}$ & & & & & 0.89 & 0.86 & $-0.03(-0.06--0.01)$ & 0.013 & 0.83 & 0.79 & $-0.04(-0.07--0.02)$ & 0.001 \\
\hline $\mathrm{FEF}_{25-75 \%} \mathrm{~L}$ & 2.25 & 2.22 & $-0.04(-0.33-0.26)$ & 0.817 & 4.00 & 3.66 & $-0.36(-0.70--0.05)$ & 0.022 & 3.31 & 3.15 & $-0.17(-0.590-0.225)$ & 0.379 \\
\hline Post-bronchodilator & & & & & 4.56 & 4.30 & $-0.30(-0.73-0.09)$ & 0.130 & 4.24 & 3.67 & $-0.59(-1.03--0.19)$ & 0.005 \\
\hline \multirow{2}{*}{\multicolumn{13}{|c|}{$\begin{array}{l}\mathrm{FEF}_{25-75 \%} \mathrm{~L} \\
\text { Smokers with asthma versus smokers without asthma }\end{array}$}} \\
\hline & & & & & & & & & & & & \\
\hline Subjects n & 203 & 40 & & & 176 & 32 & & & 142 & 30 & & \\
\hline $\mathrm{FEV}_{1} \mathrm{~L}$ & 2.03 & 2.01 & $-0.03(-0.17-0.11)$ & 0.704 & 4.00 & 3.73 & $-0.28(-0.43--0.13)$ & $<0.001$ & 3.93 & 3.74 & $-0.21(-0.40--0.01)$ & 0.036 \\
\hline $\begin{array}{l}\text { Post-bronchodilator } \\
\mathrm{FEV}_{1} \mathrm{~L}\end{array}$ & & & & & 4.18 & 4.03 & $-0.17(-0.37-0.03)$ & 0.098 & 4.08 & 3.95 & $-0.15(-0.35-0.06)$ & 0.153 \\
\hline FVC L & 2.28 & 2.32 & $0.04(-0.12-0.20)$ & 0.618 & 4,59 & 4,60 & $0.01(-0.17-0.19)$ & 0.916 & 4.97 & 4.96 & $-0.01(-0.24-0.22)$ & 0.922 \\
\hline $\begin{array}{l}\text { Post-bronchodilator } \\
\text { FVC L }\end{array}$ & & & & & 4.66 & 4.71 & $0.05(-0.18-0.29)$ & 0.658 & 4.93 & 5.03 & $0.10(-0.13-0.34)$ & 0.386 \\
\hline $\mathrm{FEV}_{1} / \mathrm{FVC}$ & 0.89 & 0.86 & $-0.03(-0.05--0.009)$ & 0.006 & 0.87 & 0.82 & $-0.05(-0.08--0.03)$ & $<0.001$ & 0.80 & 0.76 & $-0.04(-0.064--0.013)$ & 0.003 \\
\hline $\begin{array}{l}\text { Post-bronchodilator } \\
\mathrm{FEV}_{1} / \mathrm{FVC}\end{array}$ & & & & & 0.90 & 0.86 & $-0.05(-0.07--0.02)$ & $<0.001$ & 0.83 & 0.79 & $-0.04(-0.07--0.02)$ & $<0.001$ \\
\hline $\mathrm{FEF}_{25-75 \%} \mathrm{~L}$ & 2.44 & 2.22 & $-0.24(0.50-0.03)$ & 0.081 & 4.47 & 3.66 & $-0.84(-1.13--0.54)$ & $<0.001$ & 3.76 & 3.15 & $-0.62(-0.99--0.26)$ & 0.001 \\
\hline $\begin{array}{l}\text { Post-bronchodilator } \\
\text { FEF }_{25-75 \%} \mathrm{~L}\end{array}$ & & & & & 4.90 & 4.30 & $-0.64(-1.01--0.27)$ & 0.001 & 4.38 & 3.67 & $-0.73(-1.10--0.36)$ & $<0.001$ \\
\hline
\end{tabular}

Data are the mean spirometry parameters pre- and post-salbutamol with mean difference $(95 \% \mathrm{Cl}$ ) and associated p-value from longitudinal modelling. Results are divided according to asthma and smoking status at 26 years: nonsmokers without asthma, nonsmokers with asthma, smokers without asthma and smokers with asthma. Results for 10 and 18 years from generalised estimating equations longitudinal model for 10-18 years adjusted for sex; results for 26 years from a similar model for 18-26 years data. Differences may not add up due to rounding. Post-bronchodilator parameters only available at 18 and 26 years. Data from 10 to 18 years represents results available for 699 participants with data at each point; for the $18-$

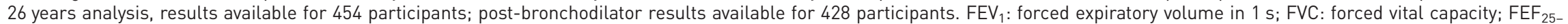
$75 \%$ : forced expiratory flow at $25-75 \%$ of FVC. 

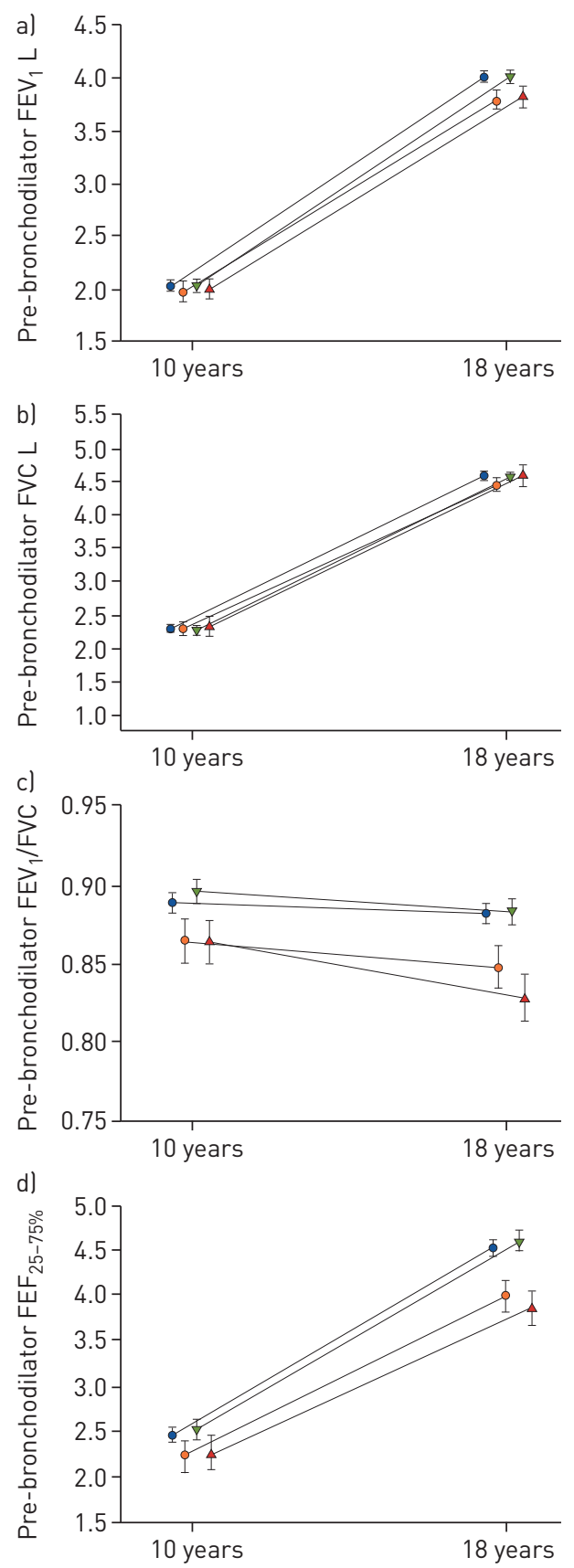
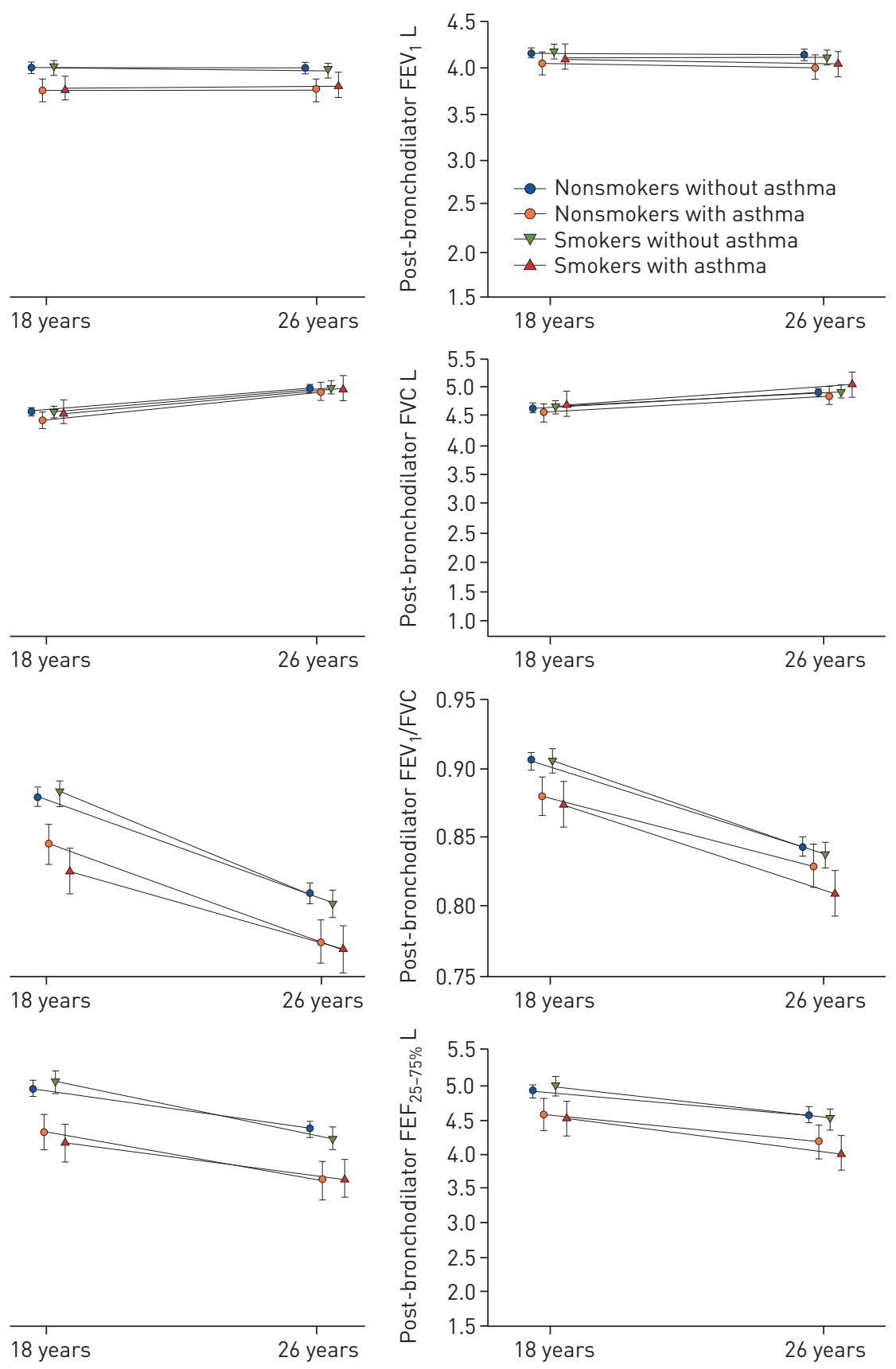

FIGURE 1 Mean values of each lung function parameter at 10, 18 and 26 years of age in smokers with asthma, nonsmokers with asthma, smokers without asthma and nonsmokers without asthma. a) Forced expiratory volume in $\left.1 \mathrm{~s}\left(\mathrm{FEV}_{1}\right), \mathrm{b}\right)$ forced vital capacity (FVC), c) $\mathrm{FEV} / \mathrm{FVC}$ ratio, d) forced expiratory flow at $25-75 \%$ of $F V C\left(\mathrm{FEF}_{25-75 \%}\right)$. Data generated from generalised estimating equations longitudinal modelling with parameters adjusted for sex. Points represent mean $(95 \% \mathrm{CI}$ ). Post-bronchodilator parameters only available at 18 and 26 years. Data from 10 to 18 years represents results available for 699 participants with data at each point; for the 18-26 years analysis, results available for 454 participants; post-bronchodilator results available for 428 participants.

without asthma had a larger drop in $\mathrm{FEF}_{25-75 \%}(-0.73$ versus $-0.50 \mathrm{~L}, \mathrm{p}<0.05)$ only between 18 and 26 years. $\mathrm{FEV}_{1}$ and $\mathrm{FEF}_{25-75 \%}$ increased less over adolescence in smokers with asthma compared to nonsmokers without asthma (1.77 versus $2.06 \mathrm{~L}, \mathrm{p}<0.01$ and 1.48 versus $2.13 \mathrm{~L}, \mathrm{p}<0.001$, respectively). Comparing further between groups, nonsmokers with asthma had a smaller increase in $\mathrm{FEV}_{1}$ and $\mathrm{FEF}_{25-75 \%}$ over adolescence than smokers without asthma ( 1.75 versus $1.95 \mathrm{~L}, \mathrm{p}<0.01$ and 1.71 versus $1.98, \mathrm{p}<0.05$, respectively).

\section{Discussion}

We examined longitudinal trajectories of lung function from age 10 years to 26 years in participants who were smoking and/or had asthma at age 26 years. Nonsmokers with asthma at 26 years had a smaller 

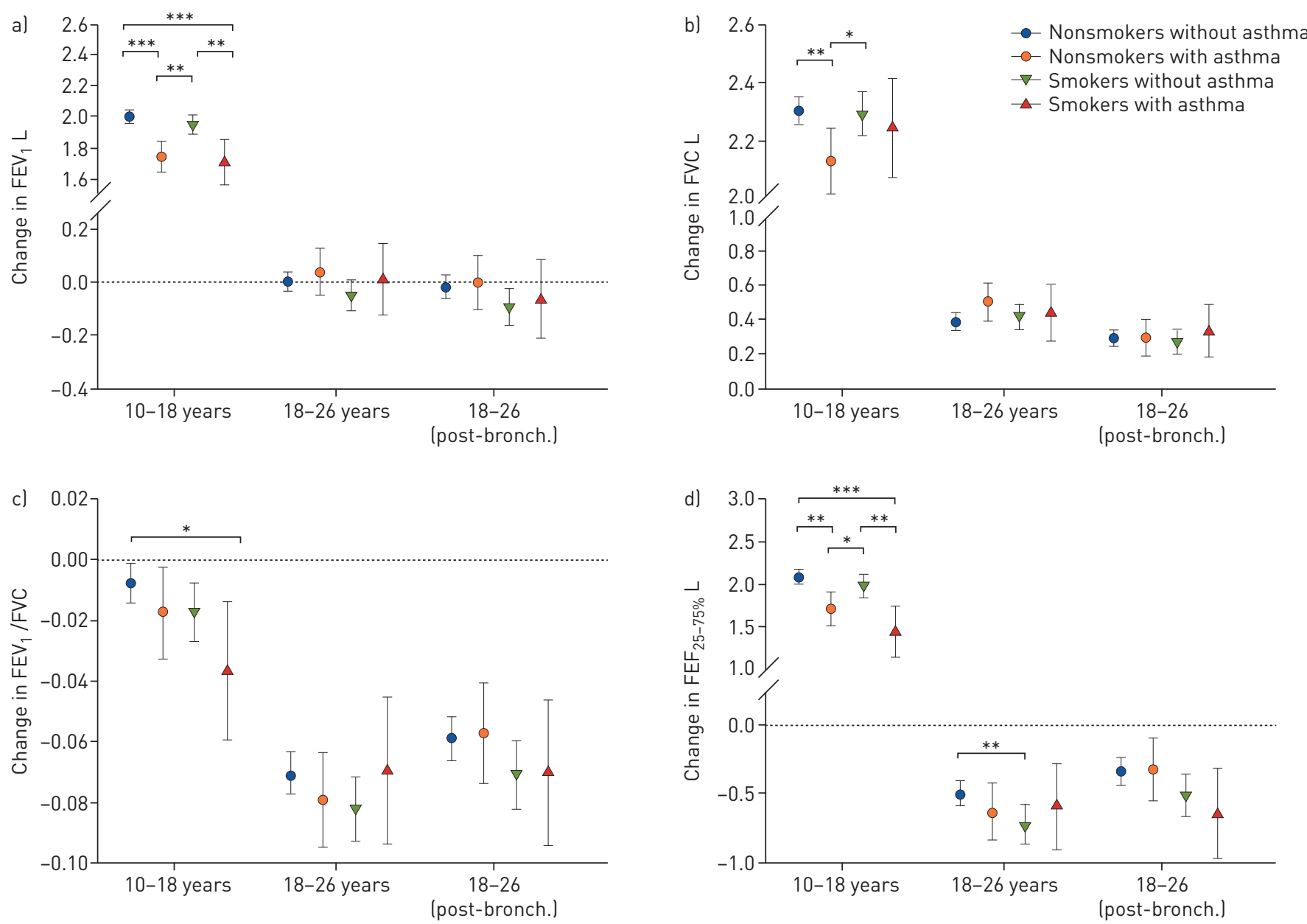

FIGURE 2 Changes in each lung function parameter from age 10 to 18 years and from age 18 to 26 years in smokers with asthma, nonsmokers with asthma, smokers without asthma and nonsmokers without asthma. a) Forced expiratory volume in $\left.1 \mathrm{~s}\left(\mathrm{FEV}_{1}\right), \mathrm{b}\right)$ forced vital capacity (FVC), c) $\mathrm{FEV}_{1} / \mathrm{FVC}$ ratio, d) forced expiratory flow at $25-75 \%$ of $F V C\left(\mathrm{FEF}_{25-75 \%}\right)$. Figures generated from a regression model with parameters adjusted for sex. Points represent mean change in lung function (95\% CI). Post-bronchodilator (post-bronch.) parameters only available at 18 and 26 years. Data from 10 to 18 years represent results from 699 participants with data at each point; for the 18-26 years analysis, results are from 454 participants; post-bronchodilator results available for 428 participants. ${ }^{*}: p<0.05 ;{ }^{* *}: p<0.01$; ${ }^{* * *}$ : $p<0.001$; between-group comparisons.

$\mathrm{FEV}_{1}, \mathrm{FEF}_{25-75 \%}$ and $\mathrm{FEV}_{1} / \mathrm{FVC}$ ratio in young adulthood with differences reduced after bronchodilator. This deficit in lung function appeared during childhood and over adolescence, but did not get worse after 18 years. In smokers without asthma, there was no difference in $\mathrm{FEV}_{1}$, although $\mathrm{FEF}_{25-75 \%}$ and $\mathrm{FEV}_{1} / \mathrm{FVC}$ ratio were lower at 26 years with the differences appearing after 18 years and showing less bronchodilator reversibility than that seen in asthma. Smokers with asthma tended to have the worst lung function.

Our study confirms that the decline in indices of lung function reflecting airway diameter $\left(\mathrm{FEV}_{1} / \mathrm{FVC}\right.$ and $\mathrm{FEF}_{25-75 \%}$ ) occurs early in adult life. While some of the apparent deficit in lung function observed in those with asthma at 26 years is reversible, there remains a degree of reduced lung function following bronchodilation, suggesting that asthma is associated with suboptimal lung growth during adolescence, the lack of complete reversibility to bronchodilator or both. Smoking young adults show a decline in lung function developing in the early twenties, which improves with bronchodilator, but remains lower than nonsmokers, indicating future potential risk of COPD. This indicates that adolescence and early adult life is a crucial period where intervention such as improved asthma treatment and smoking cessation might interrupt a downward trajectory, which otherwise could lead to fixed airflow limitation.

Asthma increases the risk of COPD later in life [16]. We and others have shown that long-term trajectories of $\mathrm{FEV}_{1}$ include the level of maximum lung function achieved and the onset and rate of subsequent decline $[17,18]$. However, participants in the study by Bus et al. [17] were only recruited at 7 years of age, limiting the quality of the early-life data. The age of onset of $\mathrm{FEV}_{1}$ decline is reported variably to be between 20 and 30 years, while the decline in $\mathrm{FEV}_{1} / \mathrm{FVC}$ starts in childhood even in those without asthma or smoking exposure $[3,19]$. Therefore, COPD could result from lack of attaining optimal 
lung function in early adulthood, as suggested by LANGE et al. [5]. In addition, we showed that young adults with asthma do not achieve optimal lung function by 18 years of age, which might put them at higher risk of future COPD. However, the subsequent rate of decline between 18 and 26 years was similar to those who did not have asthma at 26 years and reversibility to bronchodilator was present. MCGEACHIE et al. [9] showed that subgroups within those with asthma behave differently and some are more likely to have lower lung function as they go into adult life than others. Grol et al. [20] examined factors determining $\mathrm{FEV}_{1}$ decline among those with asthma. However, neither of these studies had a control group of no asthma for comparison and they did not look specifically for the effect of smoking.

JAMEs et al. [21] studied the association of both asthma and smoking on lung function. $\mathrm{FEV}_{1}$ was lower at age 19 years with asthma, but not in smokers; however, those with asthma and smoking had the worst outcome with later follow-up confirming their more rapid decline in $\mathrm{FEV}_{1}$. This is consistent with our study, where smoking participants with asthma have worst lung function and are less response to bronchodilator. AANERUD et al. [22] found a 20-fold increase in the risk of adult airway obstruction in early-onset asthma. This is supported by our observation of lower lung function at age 10 years in those with asthma at age 26 years, highlighting the importance of asthma as a major determinant of lower lung function trajectory during adolescence and adult life.

We analysed $\mathrm{FEF}_{25-75 \%}$ as an indicator of small airway disease, which is affected early in smoking-related lung disease [23]. The $\mathrm{FEF}_{25-75 \%}$ paralleled changes in $\mathrm{FEV}_{1} / \mathrm{FVC}$ ratio and was highly sensitive to changes occurring with age and with smoking and asthma. Previous studies showed a decline in $\mathrm{FEV}_{1}$ in smokers starting in their mid-twenties or later [1, 24, 25]. Using $\mathrm{FEF}_{25-75 \%}$ we have shown that the decline starts earlier than previously thought with impairment by the mid-twenties despite preserved bronchodilator reversibility.

BeLgrave et al. [26] examined childhood trajectories of $\mathrm{FEV}_{1}$, and showed that the persistently low $\mathrm{FEV}_{1}$ trajectory is associated with severe wheezing exacerbations, early allergic sensitisation and tobacco smoke exposure in early life. In addition, results from the Tucson birth cohort identified a low lung function trajectory in early adult life, predisposed by maternal asthma, early-life lower respiratory illness and current asthma [27]. In contrast, we have focused on adolescent and early adult life factors of asthma and smoking exposure.

The strengths of our study include prospective follow-up from birth, homogenous population, extensive characterisation including standardised questionnaires and high retention, thus avoiding misclassification. We defined our asthma and smoking groups based on participants' status at 26 years. Asthma is a dynamic condition where some people improve while others develop asthma at various ages. Similarly, smoking status can change over time. Thus, not all those defined as having asthma and smokers in this study had asthma or were smoking between 10 and 26 years. Sample size constraints did not allow further subgroups based on duration of asthma or smoking. However, the purpose of this analysis was to focus on those who were smoking or had asthma or both in their young adult life, and retrospectively look at their lung function pattern in order to assess their risk of future respiratory health, particularly potential risk of COPD. Another potential limitation is of recall bias as smokers with asthma were assessed using questionnaires. However, as we defined asthma and smoking status at age 26 years, recall bias is less likely.

In our cohort, the decline in $\mathrm{FEV}_{1} / \mathrm{FVC}$ occurred in all groups, but it was most prominent between 18 and 26 years and worst in smokers with asthma at 26 years (figures 1 and 2). Given that the normal range of this ratio changes with age $[15,28]$, an $\mathrm{FEV}_{1} / \mathrm{FVC}$ ratio of 0.75 would be considered abnormal at 30 years of age. It is therefore concerning to note that $39(7.3 \%)$ participants in our cohort had a post-bronchodilator $\mathrm{FEV}_{1} / \mathrm{FVC}$ of $<0.75$ at 26 years. Further assessment of this cohort should focus on this group to get a more detailed assessment of their respiratory health, with full lung function tests and imaging to assess signs of structural damage.

In summary, 1) presence of asthma at the age of 26 years in nonsmokers and smokers is associated with a lower lung function, which can be tracked back to the ages of 10 and 18 years; 2) presence of smoking at the age of 26 years in non-asthmatics and asthmatics is associated with a lower lung function, which can be tracked back to the age of 18 years; and 3) individuals with a combination of asthma and smoking at the age of 26 years had the worst lung function. There was less bronchodilator reversibility in smokers than those with asthma. Early identification of those who are at high risk of COPD, due to asthma, smoking or both, should provide a focus for strategies aimed at preventing long-term lung damage and future morbidity.

Acknowledgements: We would like to acknowledge the help of all the staff at the David Hide Asthma and Allergy Research Centre in undertaking the assessments of the Isle of Wight birth cohort. We are specifically indebted to the research team, including Stephen Potter, Susan Grevatt, Gill Glasby, Kaisha Bennett, Debbie Fraser, Nicky Tongue and Sharon Matthews. Our sincere thanks to the participants and their families who helped us with this project over the past three decades. 
Support statement: The Isle of Wight Birth Cohort assessments have been supported by the National Institutes of Health, USA (grant number R01 HL082925), Asthma UK (grant number 364) and the David Hide Asthma and Allergy Research Trust. Funding information for this article has been deposited with the Crossref Funder Registry.

Conflict of interest: None declared.

\section{References}

1 Kohansal R, Martinez-Camblor P, Agustí A, et al. The natural history of chronic airflow obstruction revisited: an analysis of the Framingham offspring cohort. Am J Respir Crit Care Med 2009; 180: 3-10.

2 Knudson RJ, Lebowitz MD, Holberg CJ, et al. Changes in the normal maximal expiratory flow-volume curve with growth and aging. Am Rev Respir Dis 1983; 127: 725-734.

3 Sears MR, Greene JM, Willan AR, et al. A longitudinal, population-based, cohort study of childhood asthma followed to adulthood. N Engl J Med 2003; 349: 1414-1422.

4 Young RP, Hopkins R, Eaton TE. Forced expiratory volume in one second: not just a lung function test but a marker of premature death from all causes. Eur Respir J 2007; 30: 616-622.

5 Lange P, Celli B, Agustí A, et al. Lung-function trajectories leading to chronic obstructive pulmonary disease. N Engl J Med 2015; 373: 111-122.

6 Fletcher C, Peto R. The natural history of chronic airflow obstruction. BMJ 1977; 1: 1645-1648.

7 Duijts L, Reiss IK, Brusselle G, et al. Early origins of chronic obstructive lung diseases across the life course. Eur J Epidemiol 2014; 29: 871-885.

8 Guerra S, Stern DA, Zhou M, et al. Combined effects of parental and active smoking on early lung function deficits: a prospective study from birth to age 26 years. Thorax 2013; 68: 1021-1028.

9 McGeachie MJ, Yates KP, Zhou X, et al. Patterns of growth and decline in lung function in persistent childhood asthma. N Engl J Med 2016; 374: 1842-1852.

10 Arshad SH, Holloway JW, Karmaus W, et al. Cohort profile: the Isle of Wight Whole Population Birth Cohort (IOWBC). Int J Epidemiol 2018; 47: 1043-1044i.

11 von Elm E, Altman DG, Egger $M$, et al. The Strengthening the Reporting of Observational Studies in Epidemiology (STROBE) statement: guidelines for reporting observational studies. J Clin Epidemiol 2008; 61: 344-349.

12 Balte P, Karmaus W, Roberts G, et al. Relationship between birth weight, maternal smoking during pregnancy and childhood and adolescent lung function: a path analysis. Respir Med 2016; 121: 13-20.

13 Scott M, Raza A, Karmaus W, et al. Influence of atopy and asthma on exhaled nitric oxide in an unselected birth cohort study. Thorax 2010; 65: 258-262.

14 Miller MR, Hankinson J, Brusasco V, et al. Standardisation of spirometry. Eur Respir J 2005; 26: 319-338.

15 Quanjer PH, Stanojevic S, Cole TJ, et al. Multi-ethnic reference values for spirometry for the 3-95-yr age range: the global lung function 2012 equations. Eur Respir J 2012; 40: 1324-1343.

16 Postma DS, Bush A, van den Berge M. Risk factors and early origins of chronic obstructive pulmonary disease. Lancet 2015; 385: 899-909.

17 Bui DS, Lodge CJ, Burgess JA, et al. Childhood predictors of lung function trajectories and future COPD risk: a prospective cohort study from the first to the sixth decade of life. Lancet Respir Med 2018; 6: 535-544.

18 Karmaus W, Mukherjee N, Janjanam VD, et al. Distinctive lung function trajectories from age 10 to 26 years in men and women and associated early life risk factors - a birth cohort study. Respir Res 2019; 20: 98.

19 Kerstjens HA, Rijcken B, Schouten JP, et al. Decline of $\mathrm{FEV}_{1}$ by age and smoking status: facts, figures, and fallacies. Thorax 1997; 52: 820-827.

20 Grol MH, Gerritsen J, Vonk JM, et al. Risk factors for growth and decline of lung function in asthmatic individuals up to age 42 years. A 30-year follow-up study. Am J Respir Crit Care Med 1999; 160: 1830-1837.

21 James AL, Palmer LJ, Kicic E, et al. Decline in lung function in the Busselton Health Study: the effects of asthma and cigarette smoking. Am J Respir Crit Care Med 2005; 171: 109-114.

22 Aanerud M, Carsin AE, Sunyer J, et al. Interaction between asthma and smoking increases the risk of adult airway obstruction. Eur Respir J 2015; 45: 635-643.

23 Aggarwal AN, Gupta D, Sharma CP, et al. Effect of household exposure to environmental tobacco smoke on airflow mechanics in asymptomatic healthy women. Indian J Med Res 2004; 119: 18-23.

24 Tager IB, Segal MR, Speizer FE, et al. The natural history of forced expiratory volumes. Effect of cigarette smoking and respiratory symptoms. Am Rev Respir Dis 1988; 138: 837-849.

25 Sherrill DL, Lebowitz MD, Knudson RJ, et al. Smoking and symptom effects on the curves of lung function growth and decline. Am Rev Respir Dis 1991; 144: 17-22.

26 Belgrave DCM, Granell R, Turner SW, et al. Lung function trajectories from pre-school age to adulthood and their associations with early life factors: a retrospective analysis of three population-based birth cohort studies. Lancet Respir Med 2018; 6: 526-534.

27 Berry CE, Billheimer D, Jenkins IC, et al. A distinct low lung function trajectory from childhood to the fourth decade of life. Am J Respir Crit Care Med 2016; 194: 607-612.

28 Swanney MP, Ruppel G, Enright PL, et al. Using the lower limit of normal for the $\mathrm{FEV}_{1} / \mathrm{FVC}$ ratio reduces the misclassification of airway obstruction. Thorax 2008; 63: 1046-1051. 